\title{
Palliative care in Ukraine — formation and development
}

\begin{abstract}
The results of research of the Association of Palliative and Hospice Care and the Ukrainian Palliative and Hospice Care League show that every year at least 600 thousand people with incurable illnesses (cancer, HIV/AIDS, diabetes, tuberculosis) need palliative care. However, nowadays the realization of the right to a dignified death for incurable patients is somewhat difficult because of numerous problems of legislative, organizational, technical, personnel and moral-ethical nature, lack of funds for proper medical care, including a shortage of palliative care institutions in Ukraine. Based on the analysis of the provision of Ukraine by palliative care institutions, it has been established that as of June 1.2017, their bed fund is about 1,500 beds, which is just over one-third of the needs recommended by the World Health Organization.

Therapy of pain syndrome is a significant problem for patients in Ukraine, which due to a number of factors such as limited availability of patients to analgesic drugs, complicated system of licensing conditions for healthcare facilities and pharmacies regarding to the storage and use of controlled substances (opioids and psychotropic medicines), and the reluctance of such establishments to obtain a license, lack of appropriate skills and experience in the treatment of chronic pain, the fear of doctors to prescribe high doses of opioids often lead to inadequate analgesia. In Ukraine morphine in tablets and in syrup was registered in 2013 and in 2017, respectively, and in 2016 oxycodone was registered.
\end{abstract}

Palliat Med Pract 2018; 12, 3: 135-142

Key words: palliative care, opioids, hospice, pain relief

\section{Introduction}

The most significant demographic problems of the modern world are the increase in the number of elderly people and the increasing of morbidity and mortality from malignant neoplasms. With the ageing of the population, the types of diseases from which people suffer and which can cause their death are changing [1-3]. According to World Health Organization (WHO) forecasts, in 2020, five major causes of death will be ischemic heart disease, stroke, chronic obstructive pulmonary disease, respiratory infections and lung cancer $[1,3,4]$. Every year more and more people die from chronic diseases, and also in the final life period in elderly patients, there is a high prob- ability of the multiple organ dysfunction syndrome development. That is why in the following groups of patients in the last stages of their life will increase the demand for palliative care (PC) [1-3].

According to the WHO definition (2002) PC is an approach that improves the quality of life of patients (adults and children) and their families facing the problems associated with life-threatening illness, through the prevention and relief of suffering by means of early identification and impeccable assessment and treatment of pain and other problems, physical, psychosocial and spiritual [2, 3, 5-7].

The results of research of the Association of Palliative and Hospice Care and the Ukrainian Palliative and Hospice Care League show that at least 600 thousand

Adres do korespondencji: Sofiya Shunkina

Danylo Halytsky Lviv National Medical University

Pekarska str. 75b, 79010 Lviv, Ukraina

sofiyaprokip@gmail.com

Palliative Medicine in Practice 2018; 12, 3, 135-142

Copyright (C) Via Medica, ISSN 2545-0425

DOI: 10.5603/PMPI.2018.0002 
people with incurable illnesses (cancer, HIV / AIDS, diabetes, tuberculosis) each year need PC. In addition, family members of patients also need professional assistance: social, psychological and spiritual support. Taking into account the relatives of patients, the number of persons requiring PC every year is approximately 1.5-2 million, so this is one of the important medical and social problems of modern society. However, the realization of the right to a dignified death for incurable patients is somewhat difficult because of numerous problems of legislative, organizational, technical, personnel and moral-ethical nature, lack of funds for proper medical care, including a shortage of PC units in Ukraine [8].

\section{Formation of palliative care in Ukraine}

The problems of incurable patients, in particular, the qualified inpatient care, proper provision of analgesics and care products, have not been considered and resolved in Ukraine at national or regional levels for a long time. Only during the last 15 years in Ukraine, mainly because of initiative of various charitable foundations, public and religious organizations, was intensively created a network of palliative medicine units (hospices and PC departments in hospitals), and also, over the last 5 years - several multidisciplinary teams were created to help patients at home.

The first hospice in Ukraine for 30 beds was opened in Lviv in 1997 (Lviv City Hospice), and it is one of the exemplary hospice units today. This year was also found hospice in Ivano-Frankivsk (Regional Hospital Hospice) and Korosten (St. Olena Hospice), in 1999 - in Kherson (Regional Hospital Hospice), in 2000 - in Kharkiv (Regional Center of Palliative Medicine "Hospice"), Zaporizhzhia (Charitable institution "Archangel Michael Hospice"), in 2002 - in Lutsk (VoIyn Regional Hospital "Hospice"). Subsequently, were created PC departments in oncology dispensaries and general hospitals, tuberculosis dispensaries and psychoneurological hospitals, palliative wards and beds at the Centers for the Prevention and Control of AIDS.

Since 2011, in Ukraine, the PC teams "Hospice at home" are established, which provide qualified care for seriously ill patients and their relatives at home, a complex of medical services, psychological and spiritual support. Today their amount is about 10 in different regions of Ukraine; however, they work mainly in region centres and big cities and physically cannot provide assistance to all patients, especially in remote areas. In 2013, in the Nadvirna city (Ivano-Frankivsk region), was opened the first and the only one in Ukraine, children's hospice for 15 beds, where it is provided specialized care to children with incurable diseases.

A significant breakthrough in the development of PC in Ukraine was the creation in 2010 of the public organization "Ukrainian Palliative and Hospice Care League" (League), which, through a long information campaign, holding conferences and symposiums, resolved the information blockade on PC problems, lobbied a number of legislative acts defining the term "PC", the order of pain relief of patients and treatment of other symptoms, as well as the procedure of prescribing of opioid analgesics. Thus, for the first time in Ukraine in 2012 with the grant support from the International Renaissance Foundation (IRF) was held National Palliative Care Congress, which presented the results of an all-Ukrainian study of the needs for PC, adopted a resolution on the strategy and development of PC in Ukraine in 2013-2022.

Over the past 5 years thanks to the assistance and cooperation of state bodies and public organizations, including League and IRF, were opened many hospices, PC departments and the work on the creation and development of PC system was intensified. However, the number of institutions available is not sufficient to fully cover the need for help to palliative patients. Thus, according to $\mathrm{WHO}$ standards, the minimum required is 100 hospice beds per 1 million inhabitants $[1,5]$. According to the expert data of the League, there are only 7 hospices, 2 centres of PC, as well as more than 60 specialized palliative departments with a total number of about 1,500 beds [9], when the minimal need, established by WHO, is at least 4000 (Tab. 1). In addition, today in Ukraine palliative and hospice departments of health care institutions are extremely limited in financing, because they receive funds mainly as charitable contributions, humanitarian aid, and do not have the ability to provide patients with necessary modern medical equipment, special anti-decubitus mattresses and other medical supplies.

In order to assess the level of availability of PC units, the calculation of the need for inpatient beds for each region of Ukraine was made and compared with the actual presence of beds. As can be seen from Table 1 Ukraine has satisfied the need for PC and psychological adaptation for only a small part of patients [10-11]. Only 6 regions (Ivano-Frankivsk, Poltava, Chernihiv, Volyn, Kyiv and Kharkiv) are provided with beds for patients requiring palliative care for two-thirds of the need, 12 regions are provided with beds from one fifth to one half, and the other 6 - less than one fifth. At the same time, inpatient PC is provided with about 1,500 beds, which is just more than one-third of the need recommended by WHO. 
Table 1. Palliative care institutions in Ukraine (as of 1.06.2017)*

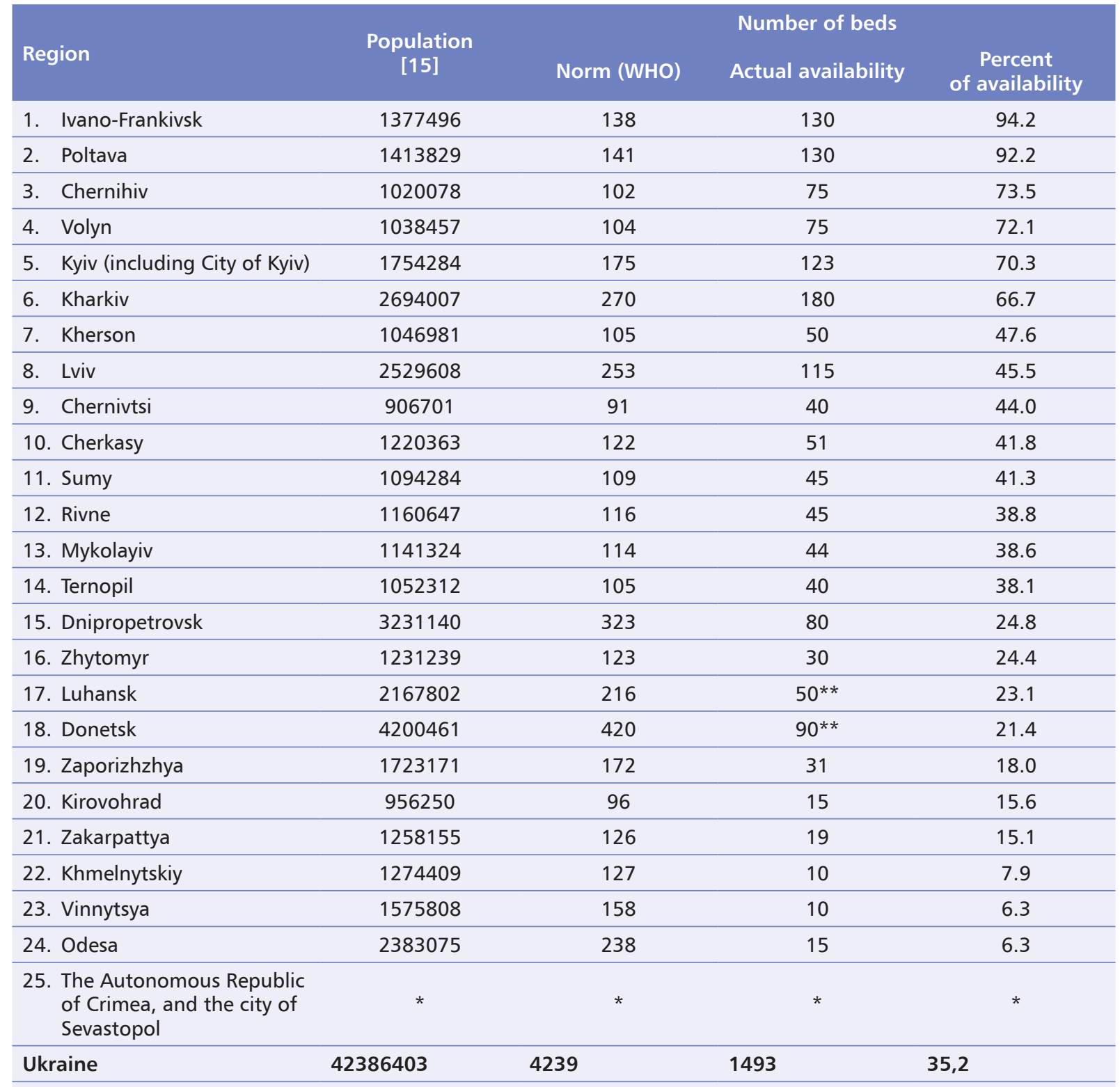

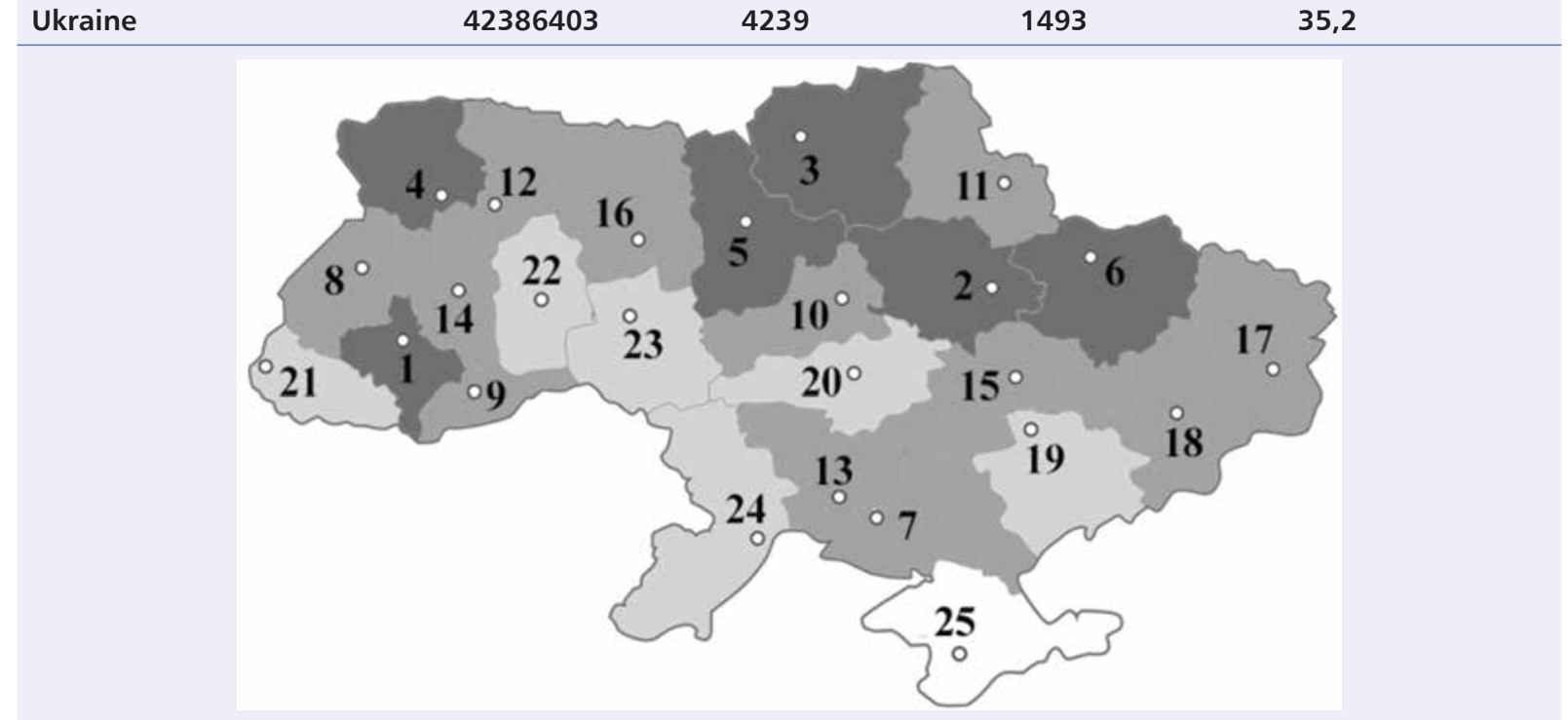

*Excluding the temporarily occupied territories of the Autonomous Republic of Crimea, and the city of Sevastopol; **as of 1.01 .2014 
Moreover, Ukraine has actually no proper care system for seriously ill patients at home, although, according to the Ministry of Health data, the majority of patients requiring palliative care (over $80 \%$ ) die at home without adequate pain relief, social and psychological support.

In order to protect the rights of patients, the project "Ensuring the protection of the rights of patients requiring palliative care by the forces of civil society organizations" was implemented in Ukraine in 2015. The project provides human rights advice to people who are in the final stages of life or their relatives. Only during February-September 2015, human rights defenders reviewed the appeals of about 500 people, the fourth part of which concerns violations of the rights of the patient, and half of these cases of violations are related to the refusal to provide adequate pain relief.

Also, in order to draw attention to the suffering of the incurable patients, their right to live out the last days with dignity, since April 2017 in Ukraine, an information campaign "Take off pink glasses" is continuing. The project was initiated by the Public Health Program of the IRF and held together with human rights organizations. The campaign has already taken place several times in different cities of Ukraine, with the involvement of chiefs and doctors of PC institutions, nurses, volunteers, and journalists.

\section{Main problems and challenges of palliative care in Ukraine}

The introduction and development of PC services in Ukraine is not possible without the creation of an appropriate legal and regulatory framework that regulates this area of medical and social care, in particular, adequate analgesia, the availability of hospices and multidisciplinary teams for patients and their families, development of human resources in PC facilities, development of private PC facilities.

Analysis of the current state and infrastructure of the PC established that its development is hampered by numerous problems of legislative, organizational, technical, personnel, moral and ethical nature. The above-mentioned problems are accompanied by a lack of money in patients and their caregivers, insufficient government funding to ensure proper care, and an acute shortage of inpatient hospice beds in the country.

Based on the research conducted by the All-Ukrainian Council for Patients' Rights and Safety and the Association of Palliative and Hospice Care [1], the following main problems of the development of the AP (please explain this abbreviation) in Ukraine can be identified:
1. Insufficient understanding by politicians, representatives of the executive power, heads of the healthcare branch of the socio-economic and humanitarian importance of PC, especially relevant due to the ageing population, an increase in the number of cancer patients, the spread of AIDS and tuberculosis epidemics.

2. Imperfect interdepartmental cooperation in the field of PC development.

3. Limited range of medicines and medical products for care and inaccessibility of them for most patients in palliative care. Particular attention is required to the critical situation with the availability of opioids, especially for patients staying at home.

4. A forbidding paradigm in the activity of law enforcing bodies in relation to opioids and opiophobia, not only among the population but also among medical professionals.

5. The lack of a proper inpatient PC network and a small number of teams to provide such care at home.

6. A small number of pharmacies, which have a license for the realization of opioids and psychotropic drugs (only 187 pharmacies from general amount 18224).

7. Barriers to adequate analgesia of patients in palliative care.

8. Insufficient number and inappropriate professional level of specialists in PC. Due to lack of qualification, the hospice staff is not always ready to provide care and patronage at the appropriate professional level. Currently, specialists working in PC institutions can acquire relevant and necessary knowledge mainly through trainings, seminars, conferences held by the public and charitable organizations. The reason for this is, basically, insufficient level of undergraduate and postgraduate training of specialists in educational institutions due to a small amount of academic hours for discipline.

9. The imperfection of the existing regulatory framework for the establishment and development of PC.

\section{Pain treatment of patients in palliative care in Ukraine}

In Ukraine, about 100,000 cancer patients and more than 5,000 AIDS patients die every year, and only $15 \%$ of them die in healthcare facilities, where they can receive the necessary specialized medical care and proper analgesia. Unfortunately, about 85\% of patients die at home. Patients and their carers remain alone with their problems such as chronic pain syndrome (CPS), organ disorders, lack of care and psychological support, loneliness, social isolation 
and insecurity due to inadequate co-ordination of the work of the healthcare institutions, an insufficient amount of hospices and multidisciplinary teams [1].

A Significant problem in PC in Ukraine is the therapy of CPS, from which are suffering about $60 \%-90 \%$ of cancer patients at the advanced stage of the disease.

The main barriers to adequate pain treatment in Ukraine are:

- factors related to the healthcare system (lack of sufficient funding; limited access of patients with CPS to analgesic drugs; absence of appropriate assortment in State Drug Formulary of oral opioids, transdermal therapeutic systems (TTS) and other dosage forms; absolutely unreasonable limitation of the maximum daily dose for injections of morphine (50 mg per day); complicated system of licensing conditions for healthcare facilities and pharmacies regarding to the storage and use of controlled substances (opioids and psychotropic medicines) and the reluctance of such institutions to get this license);

- factors associated with medical personnel (inadequate assessment of CPS; fear of high doses of opioids); unwillingness and inability to properly prescribe opioids for patients; lack of appropriate skills and experience in CPS treatment;

- factors related to the patient and family (non-compliance with drug therapy) $[1,12,13]$.

A significant barrier to adequate pain relief was the regulatory framework, which, thanks to the considerable efforts of the IRF, Ministry of Health, League and other human rights organizations, was simplified only in 2014 in regards to the prescribing and receiving of opioids, in particular: doctors have the right to prescribe opioids without any additional hospital commission; the amount of opioid in one prescription has been increased to the required for a 15-day course of treatment (earlier one prescription could contain maximum 10 tablets of $10 \mathrm{mg}$ morphine or 20 tablets of $5 \mathrm{mg}$ ). However, despite the fact that the rules of prescribing are simplified and the patient can get a prescription, very often there are difficulties during the purchase of the medicines: either there is no analgesic in the pharmacy, or a pharmacy is one in the whole region and patient needs to go to another city. Therefore, despite the legislative changes, the Ministry of Health of Ukraine and human rights organizations still record the facts of ill-treatment of patients who, due to lack of proper access to analgesics, suffer from severe CPS.

Another obstacle in achieving adequate analgesia is the range of opioids and their dosage forms on the pharmaceutical market. Only in 2013 morphine in tablets (immediate release tablets of $5 \mathrm{mg}$ and $10 \mathrm{mg}$ ) was first registered in Ukraine [14], which was a significant breakthrough in domestic pain therapy. Regardless of the registration status, due to the conflicts in instructions for medical use, in Ukraine, there is no fentanyl in the form of transdermal patches. In 2016 oxycodone tablets were first registered and finally, in 2017, morphine in the form of syrup was first registered in Ukraine - the only dosage form that is optimal for use in children.

According to the data of State Register of Medicines in Ukraine (Tab. 2), as of December 2017, 10 international nonproprietary names (INN) of opioids (29 trade names - TN) were registered, two of them are combinations. Ukraine produces almost all INN, with the exception of the oxycodone and dextropropoxyphene. The largest share in the number of registered TN accounts for nalbuphine (24.1\%), morphine, fentanyl (17.2\%) and tramadol (14.0\%).

The most of TN (16 or $53.3 \%$ ) are produced in Ukraine, the rest (14) in foreign countries (Fig. 1). Among foreign countries, Latvia occupies the largest share (16.2\%), Slovakia - 8.1\%, Germany, India and France have $5.4 \%$.

Among the manufacturers (Fig. 2), the largest share belongs to the domestic companies (Zdorovye Narodu Ltd. (27\% of all TN), Farmak JSC (8.1\%) and InterChem SLC (5.4\%), as well as foreign ones - HBM Pharma (Slovakia), AS Grindeks and AS Calcex (both - Latvia) (by $8.1 \%$, joint production), Acino Pharma AG (Switzerland) (5.4\%).

Opioids are produced as following dosage forms: oral solution, oral tablets (immediate release and extended release), capsules, sublingual tablets, transdermal patches, solution for injection (Fig. 3). The largest group among the dosage forms has a solution for injection (61.2\%), the second is a group of oral forms (tablets, prolonged-release tablets, sublingual tablets, capsules and oral solution) (29.1\%). The smallest group form transdermal patches (9.7\%).

\section{Conclusions}

1. The Ukrainian system of palliative care for patients is relatively young, since during the last 15 years, mainly through the initiative of various public and religious organizations, charitable foundations, a network of inpatient palliative care institutions was established, as well as outpatient multidisciplinary teams to help patients at home.

2. The development of palliative medicine in the country is hampered by numerous legislative and organizational problems, in particular: the lack of a proper PC network and a small number of the 
Table 2. An assortment of the trade names of opioids from the group NO2A Opioids, approved for use in Ukraine

\begin{tabular}{|c|c|c|c|c|}
\hline \multirow{2}{*}{$\begin{array}{l}\text { International } \\
\text { Nonproprietary Names }\end{array}$} & \multirow{2}{*}{ ATC code } & \multirow{2}{*}{ Registered dosage forms } & \multicolumn{2}{|c|}{ Number of registered TN } \\
\hline & & & unit & $\%$ \\
\hline Morphine & N02A A01 & $\begin{array}{l}\text { Tablets, solution for injection, } \\
\text { oral solution }\end{array}$ & 5 & 17.2 \\
\hline Oxycodone & N02A A05 & Prolonged-release tablets & 1 & 3.4 \\
\hline $\begin{array}{l}\text { Morphine, combinations } \\
\text { (unclear what cobinations) }\end{array}$ & N02A A51 & Solution for injection & 1 & 3.4 \\
\hline Fentanyl & N02A B03 & $\begin{array}{l}\text { Solution for injection, } \\
\text { transdermal patches }\end{array}$ & 5 & 17.2 \\
\hline Trimeperidine (pethidine) & N02A B04 & Solution for injection & 2 & 6.9 \\
\hline $\begin{array}{l}\text { Dextropropoxyphene } \\
\text { combinations (as above) } \\
\text { excluding psycholeptics }\end{array}$ & N02A C54 & Tablets & 1 & 3.4 \\
\hline Buprenorphine & N02A E01 & $\begin{array}{l}\text { Solution for injection, } \\
\text { sublingual tablets }\end{array}$ & 2 & 6.9 \\
\hline Butorphanol & N02A F01 & Solution for injection & 1 & 3.4 \\
\hline Nalbuphine & N02A F02 & Solution for injection & 7 & 24.1 \\
\hline Tramadol & N02A X02 & Solution for injection, capsules & 4 & 14.0 \\
\hline Total & $\mathrm{x}$ & & 29 & 99.9 \\
\hline
\end{tabular}

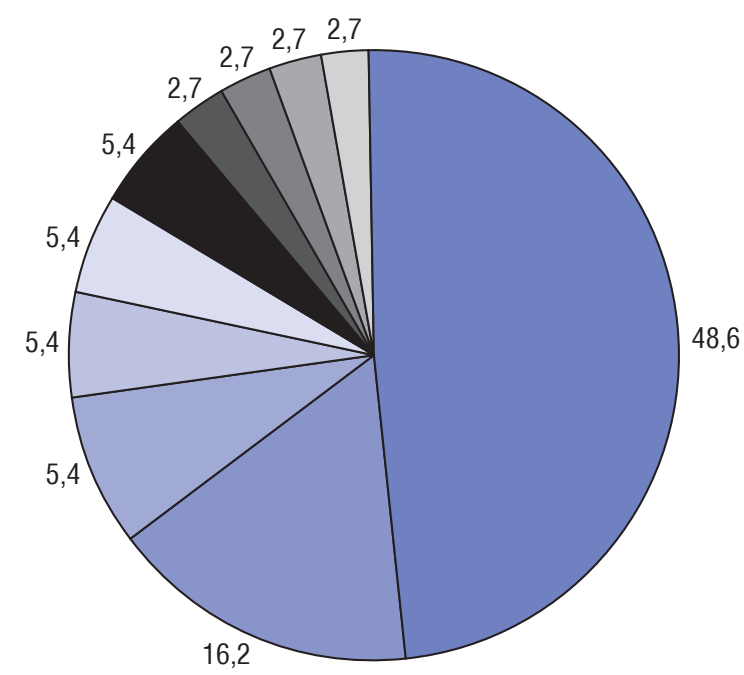

$\square$ Ukraine
$\square$ Latvia
$\square$ Slovakia
$\square$ Germany
$\square$ India
$\square$ France
$\square$ Switzerland
$\square$ Italy
$\square$ Belgium
$\square$ Republic of Korea

Figure 1. Countries-manufacturers of opioids presented at the pharmaceutical market of Ukraine (\%)

teams to provide such assistance at home; limited availability of patients with CPS to analgesics; opiophobia not only among the population, but also among medical staff; imperfection of the existing regulatory framework.

3. In Ukraine, according to the needs recommended by WHO, there are not enough specialized medical facilities to provide PC - about 1,500 beds, which is just over a third of the need. Only 6 regions are equipped with palliative care beds for patients for two-thirds of the need, 12 regions are provided with beds from one fifth to one half, and the other 6 - less than one fifth.

4. The analysis of data of the State Register of Medicines established that in Ukraine there are 10 INNs of opioids (29 TN, two of which are combinations), more than half of which (53.3\%) are produced in Ukraine. 


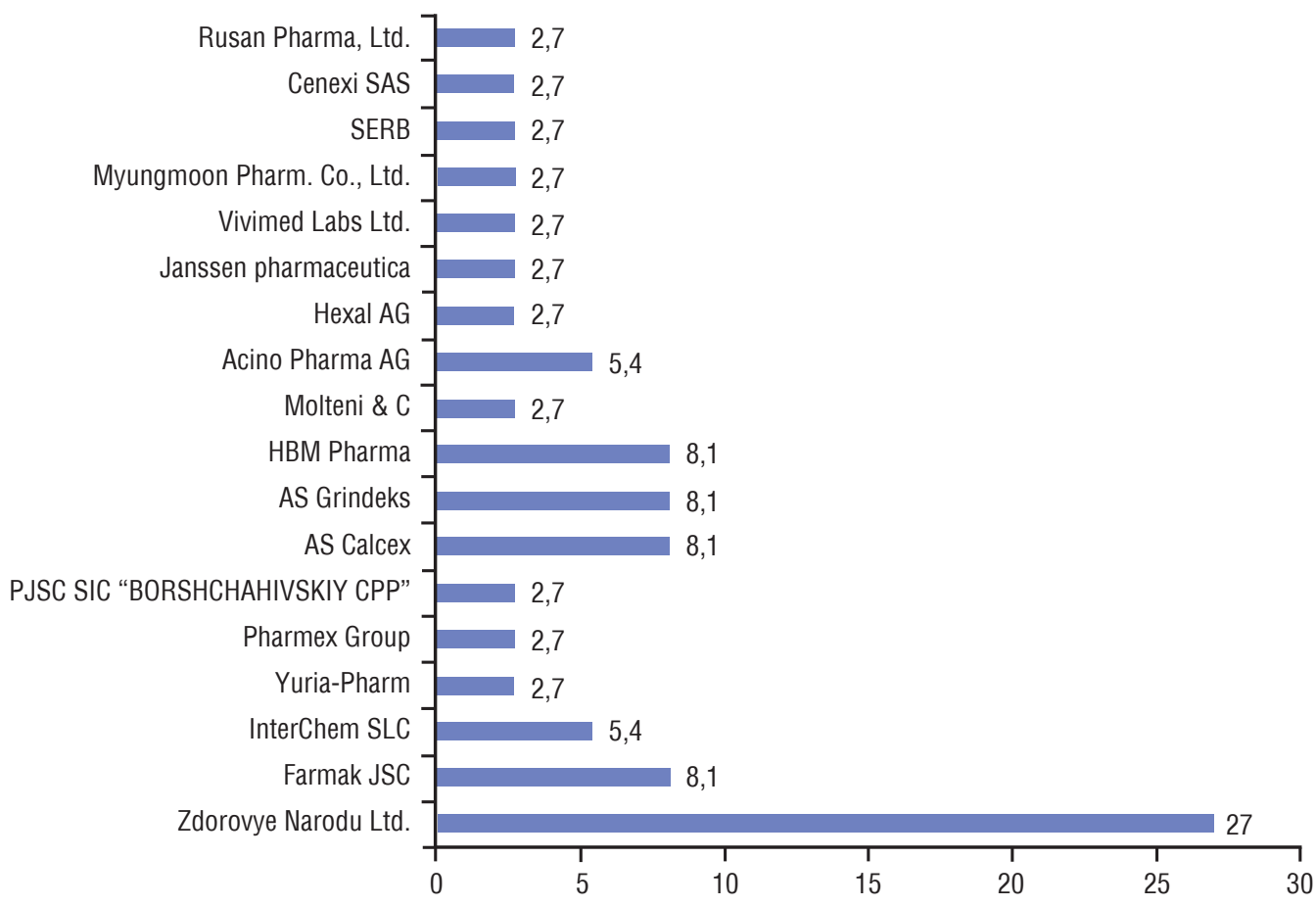

Figure 2. Companies - manufacturers of opioids presented at the pharmaceutical market of Ukraine (\%)

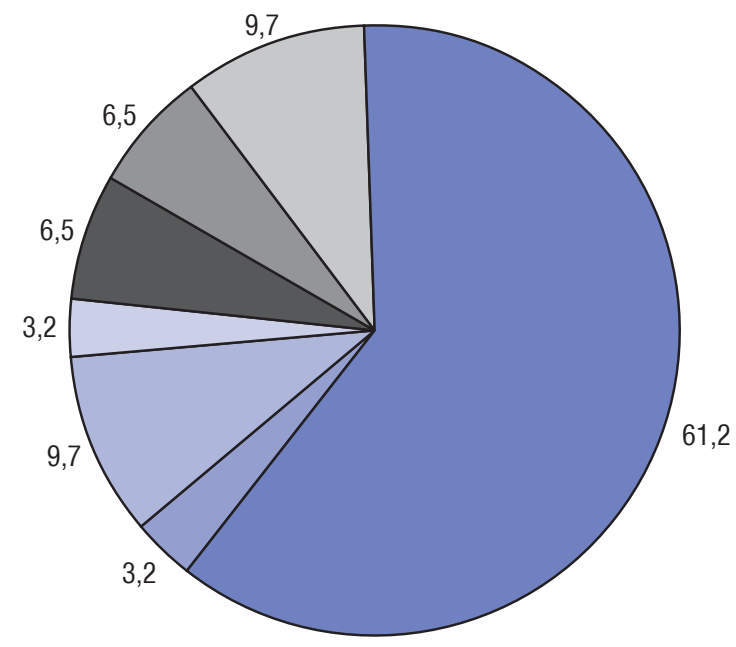

Solution for injection

$\square$ Oral solution

$\square$ Tablets

$\square$ Prolonged-release tablets

Sublingual tablets

Capsules

Transdermal parches

Figure 3. Dosage forms of opioids presented at the pharmaceutical market of Ukraine (\%)

\section{References}

1. Hubsky Yu, Tsarenko A, Skoryna O, et al. Actual issues of implementation of palliative care system and provision of rights to patients with limited prognosis of life in Ukraine. Kharkiv human rights group. "Human rights". 2008: 224-226, doi: 10.5040/9781472564443.0005.

2. World Health Organization. Better Palliative Care for Older People. 40 p. http://www.euro.who.int/ data/assets/pdf file/0009/98235/E82933.pdf?ua=1 (2004).

3. World Health Organization. Palliative care. The solid facts. 32 p. http://www.euro.who.int/en/publications/abstracts/palliative-care.-the-solid-facts (2004)
4. World Health Organization. International Organization. 2009; 10(04): 642, doi: 10.1017/s002081830000120x.

5. EAPC white paper on standards and norms for hospice and palliative care in Europe. Recommendations from the European Association for Palliative Care - European Journal of Palliative Care. http://www.eapcnet.eu/LinkClick.aspx?fileticket $=f 63 p X X z V N E Y \% 3 d$ \&tabid $=735$.

6. Foley K. The Past and Future of Palliative Care. Hastings Center Report. 2005; 35: s42-s46, doi: 10.1353/hcr.2005.0092.

7. WHO Definition of Palliative Care. http://www.who.int/cancer/palliative/definition/en/.

8. Ukrainian Palliative and Hospice Care League. http://en.ligalife.com.ual. 
9. Palliative care in Ukraine. http://ligalife.com.ua/208/.

10. Map of institutions of palliative care of Ukraine. http:// ligalife.com.ua/26/.

11. Licensing register of pharmacies which carry out economic activities on the turnover of narcotic drugs, psychotropic substances and precursors. http://usuan.dls.gov.ual.

12. Hromovyk B, Prokip S. Problematic issues of organization and pharmaceutical provision of palliative and hospice care in Ukraine. Management, Economics and Quality Assurance in Pharmacy. 2012; 2: 54-59.
13. Prokip S, Hromovyk B. Affordability of pain-killers in Ukraine as a barrier to adequate pain management. East-European Congress of Pain; Yalta, Crimea, Ukraine. September 18-20, 2013: 50-51.

14. On State Registration (Re-registration) of Medicinal Products and Changes to Registration Materials: Order of the Ministry of Health of Ukraine No. 77. http://www.moz. gov.ua/ua/portal/dn_20130201_0077.html (01.02.2013).

15. resource access service. SpringerReference. , doi: $10.1007 /$ springerreference 23626 . 